to a mixed anaerobic infection has recently been described elsewhere. ${ }^{1}$ This patient was not cured by repeated drainage, mastoidectomy, and successive treatment with penicillin, chloramphenicol, lincomycin, and co-trimoxazole over a sevenmonth period. Further drainage plus treatment with metronidazole $0.4 \mathrm{~g} 8$-hourly resulted in resolution of the lesion within 12 days with no recurrence in the past 18 months.

The outstanding feature of the treatment of these patients with metronidazole was the rapid clinical and bacteriological response a phenomenon noted in other publications. ${ }^{1-3}$ This, in our opinion, justifies further evaluation of this agent in the treatment of infections due to susceptible anaerobes. The possible association of peripheral sensory neuropathy with long-term, high-dosage treatment with metronidazole has to ou knowledge been reported in the literature on only two previous occasions. ${ }^{45}$ The limited evidence available suggests that if metronidazole causes peripheral neuropathy it does so only in patients receiving a high total dosage, and withdrawal or reduction in dosage of the agent when symptoms first appear results in complete recovery. Furthermore, our experience in the third case reported indicated that a lower total dosage is therapeutically effective.

H R INGHAM

J B SELKON

S C SO

R WEISER

Departments of Microbiology, Neurosurgery,

and Neurology,
Newcastle General Hospital, and

Regional Public Health Laboratory,

Newcastle upon Tyne

1 Ingham, H. R., et al., fournal of Antimicrobial Chemotherapy, 1975, i, 235.

California Medicine, 1972, and Finegold, S. M. Willis A Thedicine, 1972, 117, 22.

Willis, A. T., et al., Lancet, 1974, 2 ,

Ramsay, 1. D., British Medical fournal, 1968, 4,706

5 Ursing. B., and Kamme, C., Lancet, 1975, 1. 775.

\section{Delayed fibrinous peritonitis after practolol} treatment

SIR,-We wish to report a further patient with fibrinous peritonitis following practolol therapy.

A man aged 57 had been treated with practolol $100 \mathrm{mg}$ three times a day from May 1972 to February 1974 for atrial fibrillation and ischaemic hypertensive heart disease. In February 1974 the drug was stopped after a myocardial infarction. He was admitted under our care in August 1975 because of acute abdominal pain and vomiting. The abdomen was slightly distended, with generalised guarding and a suggestion of a mass to the left of the midline. Bowel sounds were occasional. Plain $x$-rays showed three dilated jejunal loops with fluid levels.

At operation the whole of the small bowel was tightly encased in a thick opaque sheet of fibrinous tissue. Plaques of the same tissue were present on the liver and parietal peritoneum. The fibrinous sheet was dissected off the small bowel, after which filmy adhesions between loops of small bowel were easily separated. The bowel and mesentery appeared normal. The patient made an uneventful recovery. Histological examination of the tissue showed fibroblasts growing into a proteinaceous base with many lymphocytes present.

We feel this case should be noted since 18 months elapsed between discontinuing practolol and presentation with fibrinous peritonitis. Previously reported cases have all occurred within eight months of taking the drug. Though the use of practolol has been discontinued, it would seem that cases may continue to be seen for some time into the future.

D ALLAN

North Lonsdale Hospital, DAvid CADE

\section{Haematemesis from metastatic carcinoma}

SIR,-The case report by $\operatorname{Dr} \mathbf{R}$ Edwards and Mr G Royle (14 June, p 598) is timely in highlighting the clinical importance of metastases to the gastric mucosa in causing symptoms. In 1966 three patients were described in whom the diagnosis of gastric metastases was indicated by barium meal and endoscopy on the finding of a centrally ulcerated mass. ${ }^{1}$ Radiologically these produced a suggestive "bullseye" sign and gastroscopy showed an elevated but smooth ulcer margin differing from primary gastric malignancy. In two of these patients the primary was bronchogenic, while in the third it was in the colon. One, presenting with massive haematemesis and melaena, had a valuable 12 months' remission following palliative partial gastrectomy.

Since then we have investigated gastric metastases due to distal spread in four further patients (two melanoma, one colon, one undifferentiated). In three others loca invasion of the stomach wall led to haematemesis and melaena due to direct spread from the splenic flexture of the colon in two ${ }^{2}$ and from a pancreatic carcinoma in the third.

Gastroenterology Unit,

Wellington,

New Zealand

Scobie, B. A., Australasian Radiology, 1966, 10, 111.

1973, 8,501.

\section{Colour disturbance as a symptom}

SIR,-The correspondence on this subject (16 August, p 436) together with personal letters $I$ have received indicate to me that more attention needs to be given to colour disturbance. The Godber Committee, which reviewed the medical standards for the fire service (Fire Service Circular 55/1971), stated that red-green colour disturbance should be a bar to service for operational firemen in order to protect themselves, their colleagues, and the public. At the same time operationa firemen over the age of 40 must be examined at three-yearly intervals. The examining doctor naturally finds himself in an unhappy dilemma when examining firemen over 40 witk. many years of fine service who happen to have red-green colour vision deficiency Operational firemen work in groups and no as individuals.

Doctors are not renowned for taking their own advice. In view of the correspondence referred to, however, and taking account of the articles by $\mathrm{Dr} W \mathrm{O} G$ Taylor $^{12}$ on the subject, I would venture with some temerity to make the following suggestions in the interests of public health.

(1) Where it is not already standard practice, medical, dental, and public health inspector students should be screened for colour vision disturbance before embarking on their training. Where such disturbance is detected the persons concerned should be given special instruction to help them with those aspects of the work in which the disturbance may present a hazard to their colleagues and the public

(2) When doctors and dentists with colour vision disturbance have graduated they should be advised about the wisdom of undertaking specialties and procedures which might put the public at risk-for example, pathology, microbiology, anaesthetics, and dermatology. The same suggestion should apply to laboratory assistants, or technicians whose occupation may jeopardize the health of the public. It might well be thought that such individuals would automatically be disinterested in pursuing the specialties referred to. Nevertheless, I have recently examined two men whose overriding ambition was to teach. physical education in schools, and especially mountaineering. Both were in firstclass physical condition, but both had epilepsy and were aware of the fact. An operational fireman has advised me that the Ishihara test cards are freely available, and if you are keen enough on work with fires you can learn the numbers by other means, a point I preferred not to pursue.

(3) Since a committee has been established to devote special attention to the health and vision of operational firemen I suggest that a corresponding committee with representatives including ophthalmologists, occupational health doctors, and community medicine doctors could with advantage be set up to investigate the problems in other occupations, including medicine.

Certainly colour disturbance is a problem that seems to be increasing with more rapid locomotion and with increasing colour codes in the electrical and aviation industries. It does seem remarkable that in this day and age anyone is free to sail a boat at night (in busy shipping lanes?). Nobody wants to be a killjoy, but when the health of the public is affected it is surely up to the medical profession to take the lead.

M J Pleydeli

Oxfordshire Area Health Authority (Teaching),

Health Office Oxford

1 Taylor, W. O. G., Practitioner, 1975, 214, 654 mology, 1971, 55, 753 .

\section{Early thymectomy for myasthenia gravis}

SIR,-May I support Mr A E Kark's comments (6 September, p 593) on the value of a minimally damaging thymectomy in justifying and encouraging its early use in myasthenia gravis? There is also a transthoracic approach in which the patient suffers negligible postoperative disability and which was devised before the advantages of the cervical approach were appreciated.

The incision lies over the left second rib, the cartilage being divided on the sternum after freeing the perichondrium and periosteum along the upper border of the rib so that it may also be divided $8 \mathrm{~cm}$ laterally and reflected caudally, preserving the pleura, which is dissected laterally from the mediastinum. The internal mammary vessels are divided. This gives direct access to the mediastinum, and gentle dissection soon mobilises the thymic lobes and their vessels. The reflected portion of the rib is replaced after thymectomy and the soft tissues are 